\title{
Effect of ketorolac and diclofenac on the impairment of endothelium-dependent relaxation induced by reactive oxygen species in rabbit abdominal aorta
}

\author{
Seung Yoon Lee ${ }^{2}$, Jung Kook Suh ${ }^{1}$, Jin Hwa Choi ${ }^{1}$, Woo Jae Jeon ${ }^{1}$, and Mi Ae Cheong ${ }^{1}$ \\ Department of Anesthesiology and Pain Medicine, ${ }^{1}$ College of Medicine, Hanyang University, Seoul, ${ }^{2}$ College of Medicine, Jeju \\ University, Jeju, Korea
}

Background: Reactive oxygen species (ROS) induce lipid peroxidation and tissue damage in endothelium. We studied the influences of ketorolac and diclofenac on ROS effects using the endothelium of rabbit abdominal aorta.

Methods: Isolated rabbit aortic rings were suspended in an organ bath filled with Krebs-Henseleit (K-H) solution bubbled with $5 \% \mathrm{CO}_{2}$ and $95 \% \mathrm{O}_{2}$ at $37.5^{\circ} \mathrm{C}$. After being stimulated to contract with phenylephrine (PE, $\left.10^{-6} \mathrm{M}\right)$, changes in arterial tension were recorded following the cumulative administration of acetylcholine (ACh, $3 \times 10^{-8}$ to $10^{-6} \mathrm{M}$ ). The percentages of ACh-induced relaxation of aortic rings before and after exposure to ROS, generated by electrolysis of $\mathrm{K}-\mathrm{H}$ solution, were used as the control and experimental values, respectively. The aortic rings were pretreated with ketorolac or diclofenac at the same concentrations $\left(10^{-5} \mathrm{M}\right.$ to $\left.3 \times 10^{-4} \mathrm{M}\right)$, and the effects of these agents were compared with the effects of ROS scavengers: catalase, mannitol, sodium salicylate and deferoxamine and the catalase inhibitor, 3-amino-1,2,4-triazole (3AT).

Results: Both ketorolac and diclofenac maintained endothlium-dependent relaxation induced by ACh in a doserelated manner inspite of ROS attack $\left(\mathrm{P}<0.05\right.$ vs. control value). The $3 \mathrm{AT}$ pretreated ketorolac $\left(3 \times 10^{-3} \mathrm{M}\right)$ group was decreased more significantly than un-pretreated ketorolac $(\mathrm{P}<0.05)$.

Conclusions: These findings suggest that ketorlac and diclofenac preserve the endothelium-dependent vasorelaxation against the attack of ROS, in a concentration-related manner. One of the endothelial protection mechanisms of ketorolac may be hydrogen peroxide scavenging. (Korean J Anesthesiol 2010; 59: 196-202)

Key Words: Catalase, Diclofenac, Endothelium, Ketorolac, Reactive oxygen species.

Received: April 29, 2010. Revised: May 19, 2010. Accepted: May 21, 2010.

Corresponding author: Jung Kook Suh, M.D., Department of Anesthesiology and Pain Medicine, College of Medicine, Hanyang University, 17, Haengdang-dong, Seongdong-gu, Seoul 133-792, Korea. Tel: 82-2-2290-8680, Fax: 82-2-2299-8692, E-mail: jksuh@hanyang.ac.kr

The 86th Annual Scientific Meeting of The Korean Society of Anesthesiologists, Poster Session P-143.

This is a theisis for a doctor's degree.

(c) This is an open-access article distributed under the terms of the Creative Commons Attribution Non-Commercial License (http:// creativecommons.org/licenses/by-nc/3.0/), which permits unrestricted non-commercial use, distribution, and reproduction in any medium, provided the original work is properly cited. 


\section{Introduction}

Certain amounts of reactive oxygen species (ROS) have been known to be generated in a normal body state, and can be also generated in large quantities by both ischemia or the oxygen resupply during ischemia reperfusion. Since ROS are not reduced by the normal anti-oxidizing system in a body, they can cause tissue reperfusion injury [1]. An oxygen $\left(\mathrm{O}_{2}\right)$ molecule generates intermediate species, including: superoxide radical $\left(\mathrm{O}_{2}{ }^{\circ}\right)$, hydrogen peroxide $\left(\mathrm{H}_{2} \mathrm{O}_{2}\right)$ and hydroxyl radical $(\mathrm{OH} \cdot)$ during the monovalent reduction reaction, and it is eventually converted to water $\left(\mathrm{H}_{2} \mathrm{O}\right)$ by catalase. In this process, the intermediates $\mathrm{O}_{2} \cdot$ and $\mathrm{OH} \cdot$ are important free radicals that cause peroxidation (LOO·) of intracellular lipids and tissue damage [2]. The most reactive $\mathrm{ROS}, \mathrm{OH} \cdot,[1]$ is produced by the Fenton reaction $\left(\mathrm{Fe}^{2+}\right.$ $+\mathrm{HOOH} \rightarrow \mathrm{Fe}^{3+}+\mathrm{OH}^{\cdot}+\mathrm{OH}^{-}$) and Haber-Weiss reaction $\left(\mathrm{O}_{2}{ }^{-}+\mathrm{NO} \cdot \rightarrow \mathrm{OONO}^{-}+\mathrm{H}^{+} \rightarrow \mathrm{OONOH} \rightarrow \mathrm{NOO} \cdot+\mathrm{OH} \cdot\right)$ [3]. It has been revealed that the ROS generated during reperfusion causes organ damage in the heart $[3,4]$, brain $[5,6]$ and blood vessels $[7,8]$.

After Furchgott and Zawadzki [9] revealed in 1980 that an endothelium-derived relaxing factor (EDRF) is released from vascular endothelium, Palmer et al. [10] proved in 1987 that the EDRF was nitric oxide (NO). Since then, it has been known that various vasoactive substances, including an endotheliumderived hyperpolarizing factor (EDHF) and an endotheliumderived contracting factor (EDCF), are discharged from vascular endothelium. Since such substances are discharged by various kinds of stimuli or a change in the conditions, vascular endothelium plays an important role in regulating vascular tone. However, because the vascular endothelium tissue is composed of a monolayer of cells, it is easily damaged by physical and chemical stimuli. Thus, the vascular endothelium tissue is the first target of ROS generated during reperfusion. Among the anesthetics currently used, inhalation anesthetics $[1,4,11]$ and lidocaine, one of the local anesthetics, are known to be able to prevent ischemia-reperfusion injury in the brain [12]. In this study, we have evaluated the effect the COX (cyclooxygenase) blockers ketorolac and diclofenac, on rabbit aorta endothelium-dependent relaxation, to examine if their anti-oxidizing effect can suppress or reduce the vascular endothelium injury by ROS.

\section{Materials and Methods}

\section{Preparation of ring slices and recording}

All experiments were conducted conforming to the regulations of the Laboratory Animal Committee. Auricular intravenous injection of heparin $600 \mathrm{IU} / \mathrm{kg}$ was carried out in the rabbits under enflurane inhalation anesthesia and exsanguinations followed after 3 minutes by cleaving the carotid artery. The abdominal aortas of the rabbits $(2-2.5 \mathrm{~kg}$, Male, $\mathrm{n}=$ 27) were extirpated and 3-4 mm long ring slices were prepared by separating the lipid tissue and connective tissue, not engaging any tension on them, in a petri dish containing KrebsHenseleit solution (K-H solution: $\mathrm{NaCl} 120.0, \mathrm{NaHCO}_{3} 25.0$, $\mathrm{KCl}$ 5.0, $\mathrm{MgSO}_{4}$ 1.2, $\mathrm{CaCl}_{2} 2.5, \mathrm{NaH}_{2} \mathrm{PO}_{4} 1.4$, glucose $11.0 \mathrm{mM}$ ) and $95 \%$ oxygen and $5 \%$ carbon dioxide were insufflated. While maintaining the temperature at $37 \pm 0.5^{\circ} \mathrm{C}$, one end of the aorta slice was fixed in the tissue bath containing $5 \mathrm{ml}$ of K-H solution, and $95 \%$ oxygen and $5 \%$ carbon dioxide was insufflated. The opposite end was connected to a force displacement transducer (TSD $125 \mathrm{C}^{\circledR}$, Biopac Inc., USA) and the K-H solution was exchanged every 15 minutes during a 90 minutes equilibration period. The resting stage tension was fixed at $1.5 \mathrm{~g}$. The vascular smooth muscle tension was recorded using an amplifier (DA100C ${ }^{\circledR}$, Biopac Inc., USA) with a data acquisition system $\left(\mathrm{MP} 100^{\circledR}\right.$, Biopac Inc., USA) and a personal computer.

Following the precontraction with phenylephrine (PE) $10^{-6}$ $\mathrm{M}$, acetylcholine (ACh) $3 \times 10^{-8}, 10^{-7}, 3 \times 10^{-7}$ and $10^{-6} \mathrm{M}$ were consecutively injected to observe the change of the aortic tone. Changes of the aortic tone by ACh injection before ROS exposure (control) and after ROS exposure (experimental) were compared.

\section{Method of exposure to ROS}

After obtaining the control group values by the consecutive injection of ACh, each reagent was pre-treated and, after a certain necessary interval, electrolysis (EL) was carried out by applying an electric current (constant current (CC), $15 \mathrm{~mA}$ ) to the positive and negative electrodes in the K-H solution for 35 seconds to generate ROS and induce vascular endothelial injury. In the procedures, more than $1 \mathrm{~cm}$ of distance was maintained between the abdominal aorta ring slices and the positive and negative electrodes to avoid a direct stimulus of the electric field to the tissue. Then, the K-H solution was exchanged, the precontrcaction by PE followed, and ACh was consecutively injected. Changes of the aortic tone were recorded as the experimental group values. The electrode was made of platinum $(7.5 \mathrm{~mm})$ and $15 \mathrm{~mA}$ of constant current generation was tested before the experiment.

\section{Vascular relaxation in the ROS scavenger pretreatment}

To examine the action of the scavenger on ROS, 1,000 U/ml of catalase (CAT, $n=8$ ), the hydrogen peroxide scavenger, was pretreated for 15 minutes. The hydroxyl radical scavengers, deferoxamine (DEF, $\mathrm{n}=9$ ) $0.1 \mathrm{mM}$, sodium salicylate (SA) 1 
$\mathrm{mM}(\mathrm{n}=8)$ and mannitol $(\mathrm{MN}) 5 \times 10^{-3} \mathrm{M}(\mathrm{n}=12)$ were also pretreated, each for 30 minutes. Then, ROS was generated by EL to induce vascular endothelium injury.

\section{Effect of ketorolac and diclofenac pretreatment}

After obtaining the control group values of the response to ACh before ROS exposure, the experimental group values were obtained by 15 minutes of experimental drug pretreatment followed by exposure to the ROS. The experimental groups included one group pretreated with ketorolac $(\mathrm{K}: \mathrm{n}=8,10,11,9)$ and the other group pretreated with diclofenac ( $\mathrm{D}: \mathrm{n}=7,12,13$, $14)$, using concentrations of $10^{-5}, 3 \times 10^{-5}, 10^{-4}$ and $3 \times 10^{-4} \mathrm{M}$.

\section{Effect of 3-amino-1,2,4-triazole (3AT) on vascular endothelial injury by ROS}

The samples were pretreated with $3 \mathrm{AT}$, the catalase inhibitor, for 30 minutes. After 15 minutes of waiting period, $3 \times 10^{-4} \mathrm{M}$ of ketorolac $(n=6)$ and diclofenac $(n=8)$ were additionally added and treatment was conducted for 15 minutes. Following 35 seconds of EL to generate ROS, ACh was consecutively injected.

\section{Reagents}

The reagents phenylephrine, acetylcholine, diclofenac, catalase, deferoxamine, sodium salicylate and mannitol, were purchased from Sigma Co. (USA). The ketorolac was Kerolmin ${ }^{\circledR}$ (Hana Pharmacy, Korea).

\section{Statistical procedure}

The percentages of ACh-induced relaxation of aortic rings were calculated and the results were used as the control group values. The data were presented as "mean \pm standard deviation." Prism 2.0 ${ }^{\circledR}$ (GraphPad software, USA) was used to obtain the dose-response curve by non-linear regression analysis. The paired t-test was used for the comparison of results before and after the ROS exposure, while an unpaired t-test was used for the comparison of the results of the 3AT pretreated group and the non-pretreated group. For the comparison of the results between the pretreated concentrations, a one-way ANOVA was used. All the post-hoc tests were carried out by the Dunnet test, defining statistical significance as $\mathrm{P}<0.05$.

\section{Results}

\section{Vascular relaxation after ROS scavenger pretreatment}

At ACh $\left(10^{-6} \mathrm{M}\right)$, the tension before ROS scavenger pretreat- ment was $-87.6 \pm 3.9 \%$ and the vascular endotheliumdependent relaxation was $-87.6 \pm 3.3,-77.6 \pm 2.3,-65.6 \pm 3.3$ and $2.0 \pm 1.8 \%$ in the catalase, deferoxamine, sodium salicylate and mannitol, respectively. The catalase group was not affected by ROS, while the relaxation was significantly reduced in the other groups when compared with that of the catalase group (P < 0.05; Fig. 1). The mannitol group did not show vascular endothelium-dependent relaxation.

\section{Vascular relaxation after vascular endothelial injury induction with ROS}

The relaxation induced by ACh $10^{-7},\left(3 \times 10^{-7}\right.$ and $10^{-6} \mathrm{M}$ groups) was significantly reduced by ketorolac $\left(10^{-5}\right.$ and $3 \times$ $10^{-5} \mathrm{M}$ ) pretreatment, when compared with relaxation before the ROS exposure $(\mathrm{P}<0.05$; Fig. 2$)$. The relaxation in the ketorolac pretreated groups $\left(3 \times 10^{-5}, 10^{-4}\right.$ and $\left.3 \times 10^{-4} \mathrm{M}\right)$ was significantly increased after the ROS exposure, in proportion to the pretreatment concentration, when compared with the relaxation in the $10^{-5} \mathrm{M}$ pretreated group $(\mathrm{P}<0.05,0.01,0.01$; Fig. 2). The relaxation of the diclofenac pretreated groups $\left(10^{-5}\right.$ and $\left.3 \times 10^{-5} \mathrm{M}\right)$ was significantly decreased at ACh $\left(10^{-7}, 3 \times 10^{-7}\right.$ and $10^{-6} \mathrm{M}$ ), and the relaxation of the diclofenac pretreated groups $\left(10^{-4}\right.$ and $\left.3 \times 10^{-4} \mathrm{M}\right)$ was significantly decreased at ACh $\left(10^{-6} \mathrm{M}\right)$ when compared with the relaxation before the ROS exposure ( $\mathrm{P}<0.05$; Fig. 3$)$. The relaxation of the diclofenac pretreated groups $\left(10^{-4}\right.$ and $\left.3 \times 10^{-4} \mathrm{M}\right)$ was significantly decreased at $\mathrm{ACh}\left(10^{-7}, 3 \times 10^{-7}\right.$ and $\left.10^{-6} \mathrm{M}\right)$, and the relaxation

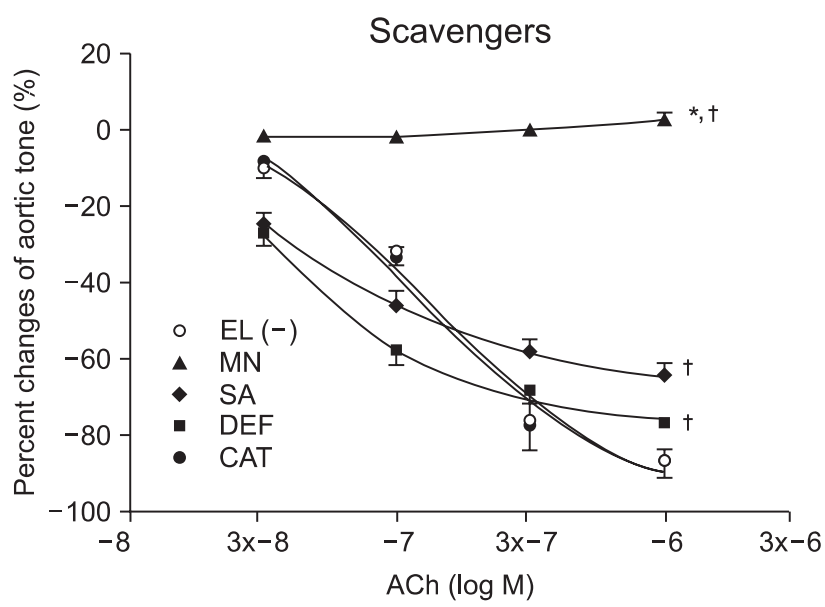

Fig. 1. The potencies of protective effects of scavengers against ROS are shown in the order of catalase (CAT, $n=8$ ), deferoxamine (DEF, $\mathrm{n}=9$ ) and sodium salicylate ( $\mathrm{SA}, \mathrm{n}=8)$, but mannitol ( $\mathrm{MN}, \mathrm{n}=12)$ has no scavenging effect. Data are expressed as mean \pm SE. ACh: acetylcholine. $\mathrm{EL}(-)$ : before electrolysis. ${ }^{*} \mathrm{P}<0.05$, compared with ACh $10^{-7}$ to $10^{-6} \mathrm{M}$ of $\mathrm{EL}(-)$. ${ }^{\dagger} \mathrm{P}<0.05$, compared with $\mathrm{ACh} 10^{-7}$ to $10^{-6} \mathrm{M}$ of the CAT Group. 


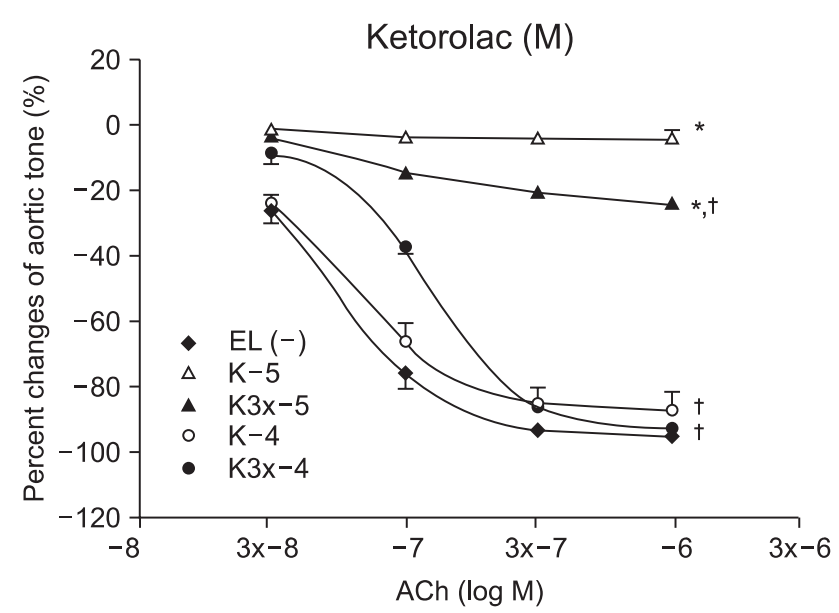

Fig. 2. Effects of ketorolac $\left(10^{-5} \mathrm{M}\right.$ : K-5, $3 \times 10^{-5} \mathrm{M}$ : K3x-5, $10^{-4} \mathrm{M}$ : $\mathrm{K}-4,3 \times 10^{-4} \mathrm{M}$ : K3x-4) on the ROS attack are shown by concentration response curves. The antioxidant effect of ketorolac against ROS attack significantly increases in a dose-dependent manner. Data are expressed as mean \pm SE. ACh: acetylcholine. $\mathrm{EL}(-)$ : before electrolysis. *P $<0.05$, compared with ACh $10^{-7}$ to $10^{-6} \mathrm{M}$ of $\operatorname{EL}(-) .{ }^{\dagger} \mathrm{P}<0.05$, compared with ACh $10^{-7}$ to $10^{-6} \mathrm{M}$ of the ketorolac $10^{-5} \mathrm{M}$ (K-5) group.

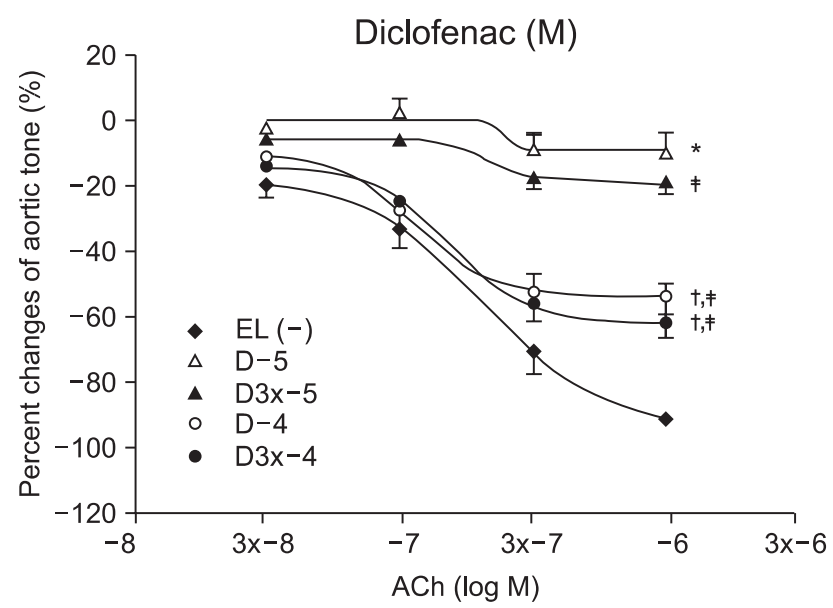

Fig. 3. Effects of diclofenac $\left(10^{-5} \mathrm{M}: \mathrm{K}-5,3 \times 10^{-5} \mathrm{M}\right.$ : K3x-5, $10^{-4} \mathrm{M}$ : $\left.\mathrm{K}-4,3 \times 10^{-4} \mathrm{M}: \mathrm{K} 3 \mathrm{x}-4\right)$ on the ROS attack are shown by concentration response curves. The antioxidant effect of diclofenac against ROS attack significantly increases in a dose-dependent manner. Data are expressed as mean $\pm \mathrm{SE}$. ACh: acetylcholine. $\operatorname{EL}(-)$ : before electrolysis. $* \mathrm{P}<0.05$, compared with ACh $10^{-7}$ to $10^{-6} \mathrm{M}$ of $\mathrm{EL}(-)$ group. ${ }^{\dagger} \mathrm{P}<0.05$, compared with $\mathrm{ACh} 10^{-7}$ to $10^{-6} \mathrm{M}$ of the diclofenac $10^{-5} \mathrm{M}(\mathrm{D}-5)$ group. ${ }^{\ddagger} \mathrm{P}<0.05$, compared with $\mathrm{EL}(-)$ group.

of the diclofenac pretreated groups $\left(10^{-4}\right.$ and $\left.3 \times 10^{-4} \mathrm{M}\right)$ was significantly increased at ACh $\left(10^{-7}, 3 \times 10^{-7}\right.$ and $\left.10^{-6} \mathrm{M}\right)$, in proportion to the pretreatment concentration, after the ROS exposure, when compared with the relaxation of the diclofenac $\left(10^{-5} \mathrm{M}\right.$ pretreated group $)(\mathrm{P}<0.01,0.01 ;$ Fig. 3$)$.

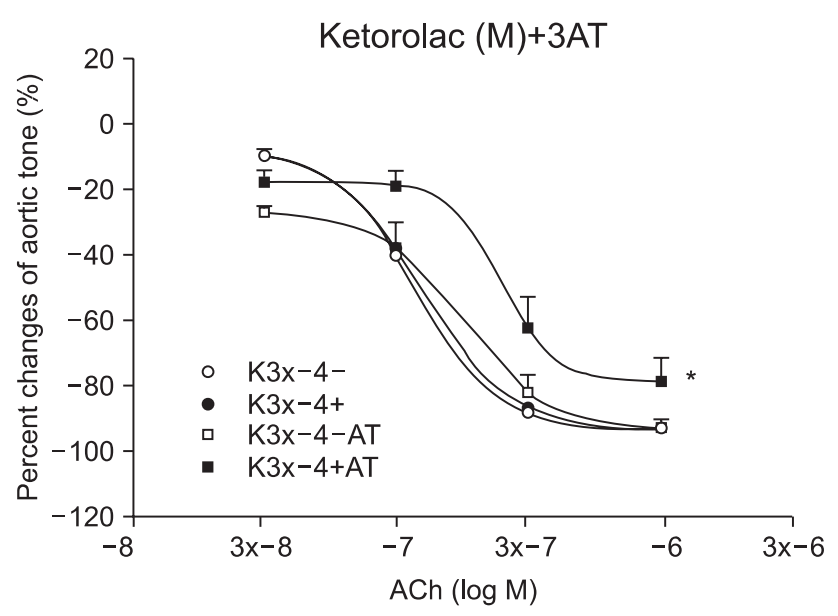

Fig. 4. Acetylcholine-induced endothelial-dependent vasorelaxation is significantly attenuated in the presence of $3 \mathrm{AT}(\mathrm{K} 3 \mathrm{X}-4+\mathrm{AT})$ compared with the 3AT un-pretreated group (K3x-4+). Data are expressed as mean \pm SE. Before electrolysis: K3x-4-, K3X-4-AT. ACh: acetylcholine. 3AT: 3-Amino-1,2,3-Triazole. ${ }^{*} \mathrm{P}<0.05$, compared with ACh $10^{-7}$ to $10^{-6} \mathrm{M}$ of the ketorolac $3 \times 10^{-4} \mathrm{M}(\mathrm{K} 3 \mathrm{x}-4+)$ group.

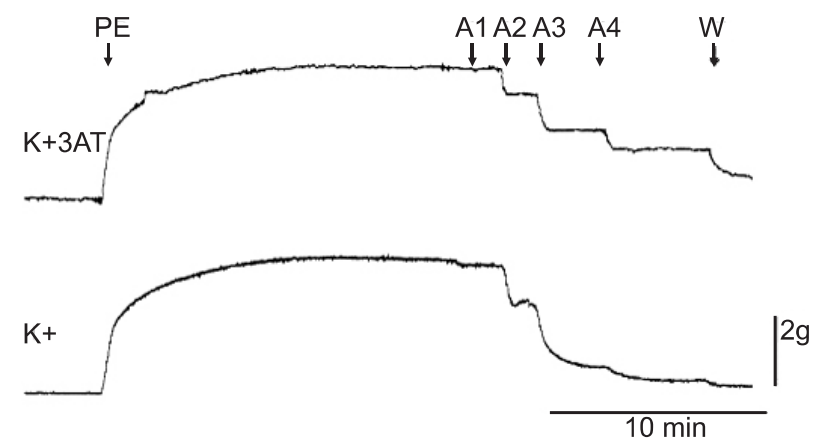

Fig. 5. Real tracings of vascular tension show impairment of ACh induced endothelial-dependent vasorelaxation in the 3AT pretreated group $(\mathrm{K}+3 \mathrm{AT})$ compared with the $3 \mathrm{AT}$ un-pretreated group $(\mathrm{K}+)$. 3AT: 3-Amino-1,2,3-Triazole (catalase inhibitor: $50 \mathrm{mM}$ ). K+3AT: 3AT pretreated for $30 \mathrm{~min}$, and ketorolac $3 \times 10^{-4} \mathrm{M}$ pretreated for $15 \mathrm{~min}$. $\mathrm{K}+$ : ketorolac $3 \times 10^{-4} \mathrm{M}$ pretreated for $15 \mathrm{~min}$. $\mathrm{PE}$ : phenylephrine $10^{-6} \mathrm{M}, \mathrm{Al}$-A4 : acetylcholine $3 \times 10^{-8}, 10^{-7}, 3 \times 10^{-7}$ and $10^{-6} \mathrm{M}$. W: wash out.

\section{Effect of $3 A T$ on the vascular endothelium injury by ROS}

In the ketorolac pretreated group $\left(3 \times 10^{-4} \mathrm{M}\right)$, which was pretreated with $3 \mathrm{AT}$, the relaxation was significantly decreased at $\operatorname{ACh}\left(10^{-7}, 3 \times 10^{-7}\right.$ and $\left.10^{-6} \mathrm{M}\right)(\mathrm{P}<0.01$; Fig. 4 and 5$)$. No significant change was found in the case of the diclofenac pretreated group $\left(3 \times 10^{-4} \mathrm{M}\right)$ which was pretreated with $3 \mathrm{AT}$ (Fig. 6). 


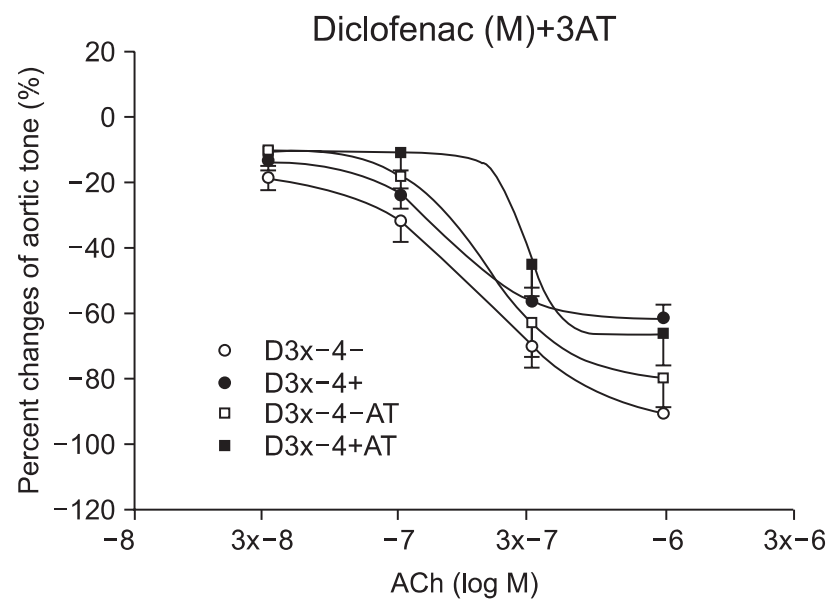

Fig. 6. In the diclofenac $3 \times 10^{-4} \mathrm{M}(\mathrm{D} 3 \mathrm{x}-4+)$ group, ACh-induced relaxation is not affected in the presence of 3AT (D3x-4+AT) when compared with that in the absence of 3AT (D3X-4+). Data are expressed as mean \pm SE. Before electrolysis: D3x-4-, D3x-4-AT. ACh: acetylcholine. 3AT: 3-Amino-1,2,3-Triazole.

\section{Discussion}

The ROS experimental method includes the process to generate ROS by direct EL of physiologic salt solution (PSS), such as K-H solution, [8] and the process to directly inject $\mathrm{H}_{2} \mathrm{O}_{2}$ to PSS [13]. It has been known that ROS, such as $\mathrm{O}_{2}{ }^{-}{ }^{-}, \mathrm{H}_{2} \mathrm{O}_{2}, \mathrm{OH} \cdot$, are generated during the PSS EL [14-17]. Although ascorbic acid $\left(1.1 \times 10^{-4} \mathrm{M}\right)$ is generally added to K-H solution it was not added in this experiment, to exclude its anti-oxidizing effect. We generated ROS by the EL method and fabricated the electrodes for this study. A number of tiny air bubbles were generated at the positive and negative electrodes when an electric current was applied. In one study, using mouse chest aorta, it was reported that 5 minutes of EL was required to induce injury by ROS [8]. However, 5 minutes of EL with $15 \mathrm{~mA}$ constant current caused too much injury by ROS in the rabbit abdominal aorta and the ROS generated by 35 seconds of EL was sufficient for our study. The implication of this experimental result is that there is an animal inter-specific variation in the degree of injury by ROS.

Lecour et al. [18] verified, in their study of the left ventricle function in a mouse heart using the Langendorff perfusion method, that the function of the left ventricle declined when ROS was generated by 1 minute of EL in K-H solution using a constant current of 1, 1.5, 3, 5, 7.5 and $10 \mathrm{~mA}$. They also carried out EL in the cuvettes, each containing $125 \mathrm{mM}$ 5,5-dimethyl1-pyrroline-N-oxide (DMPO), and quantitatively analyzed the signal of the adduct, DMPO-OH, using the electron spin resonance (ESR) method. In addition, they found that superoxide radicals and hydroxyl radicals were generated by the EL of K-H solution from the ESR experiments with the groups pretreated with superoxide dismutase (SOD : $100 \mathrm{IU} /$ $\mathrm{ml}$ ) and mannitol (50 $\mathrm{mM})$, respectively. The DMPO-OH signal was found starting from 10 seconds after initiation of EL, stably generated until 60 seconds, when the EL was finished, and reduced afterward. In the case of SOD pretreatement, the DMPO-OH signal was reduced by $60 \%$, which showed that the generation of hydroxyl radicals was partially by the Fenton reaction of a superoxide radical. On the contrary, the DMPO-OH signal was not found in the case of mannitol (50 $\mathrm{mM}$ ) pretreatment. However, Lecour et al. reported that no significant difference in the cardiac parameter was found when the experiment was performed using the Langendorff perfusion method, in the group pre-treated with mannitol, a known hydroxyl radical scavenger, 15 minutes after the EL or the control group [18]. Similarly, in the scavenger pretreatment experiments in this study, pretreatment with mannitol could not prevent the vascular endothelium dysfunction by the ROS, in contrast to other scavengers' pretreatment.

The constant current applied for the quantitative analysis of the DMPO-OH signal by ESR was 1-40 mA, and the DMPO-OH signal corresponding to the amount of the generated hydroxyl radical was proportional to the magnitude of the constant current. In this experiment, $15 \mathrm{~mA}$ of a constant current was generated with a constant current amplifier to perform the EL for 35 seconds.

ROS is also generated as the result of cyclooxygenase (COX) action during inflammatory response [19]. Other major sources of ROS and reactive nitrogen species (RNS) formed during inflammatory response include vascular endothelium, Kuffer cells, neutrophils and macrophages. ROS and RNS are generated as the result of antagonizing infectious pathogenic bacteria in those cells. When ROS or RNS is continuously generated, or the anti-oxidizing defensive reaction is reduced, cancers, rheumatoid arthritis or organ transplantation rejection can result. The same diseases can be caused when the inflammatory response is extremely high, since the ROS, including peroxyl radicals ( $\mathrm{ROO} \cdot), \mathrm{OH} \cdot \mathrm{O}_{2} \cdot{ }^{-}, \mathrm{H}_{2} \mathrm{O}_{2}$ and hypochlorous acid ( $\mathrm{HOCl}$ ), and RNS, including nitric oxide ( $\mathrm{NO})$ and peroxynitrite anion $\left(\mathrm{ONOO}^{-}\right)$, are increased. Thus, these are the pathophysiological findings of the above mentioned diseases, as well as the treatment targets. It has been known that indomethacin, the COX 1 and 2 blocker, can scavenge $\mathrm{OH} \cdot \mathrm{O}_{2}{ }^{-{ }^{-}}$, NO and $\mathrm{ONOO}^{-}$ [19]. The half maximal inhibitory concentrations $\left(\mathrm{IC}_{50}\right)$ for the hydroxyl radical scavenging activity of indomethacin, ketorolac and mannitol were $12 \pm 2 \mu \mathrm{M}, 61 \pm 7 \mu \mathrm{M}$ and 3,272 $\pm 215 \mu \mathrm{M}$, respectively, indicating that the $\mathrm{IC}_{50}$ of mannitol was about 50 times higher than that of ketorolac [19].

It was reported that vascular relaxation induced by ACh is caused by induced release of NO in the vascular endothelium and that ROS inactivates NO [20,21]. In addition, the ROS generated by ischemia or reperfusion causes the vascular 
endothelium injury $[15,22]$. In this experiment, after ROS was generated by 35 seconds of EL, the K-H solution was replaced by a new solution and the measurement was carried out after 15 minutes of the equilibrium period. Since the measurement was done after the ROS was removed in this manner, blocking of the Ach vascular relaxation induction effect is assumed to be the result of the direct vascular endothelium injury by ROS, not the result of NO inactivation by ROS [20].

Because vascular endothelium tissue, a monolayer of cells, can be easily damaged, release of various vasoactive substances from vascular endothelium is impossible in the case of chronic hypertension, due to the damage, including the detachment of the vascular endothelium [23]. In this case, only smooth muscles exist in the blood vessel and they are directly damaged by the generated ROS. Thus, more studies are required regarding the damage of vascular smooth muscles.

In an oxygen depleted environment, such as ischemia or cardiac standstill, ATP in vascular endothelium is rapidly consumed, causing failure of the $\mathrm{Na}^{+}-\mathrm{K}^{+}$ATPase pump and an increase of intracellular $\left[\mathrm{Na}^{+}\right] \mathrm{i}$ and $\left[\mathrm{H}^{+}\right] \mathrm{I}$ by inhibiting removal of the metabolites and by mitochondrial NADH oxidation. Increased intracellular $\left[\mathrm{H}^{+}\right] \mathrm{i}$ leads to an increase of $\left[\mathrm{Na}^{+}\right]$ i by facilitating the $\mathrm{Na}^{+}-\mathrm{H}^{+}$exchange for the maintenance of constant $[\mathrm{pH}] \mathrm{I}$, thus triggering the $\mathrm{Na}^{+}-\mathrm{Ca}^{2+}$ exchange and increasing $\left[\mathrm{Ca}^{2+}\right] \mathrm{i}[24]$. Increase of $\left[\mathrm{Ca}^{2+}\right]$ i deforms the proteins and phospholipids [25]. In other words, increase of $\left[\mathrm{Ca}^{2+}\right] \mathrm{i}$ activates phospholipase $\mathrm{A}_{2}\left(\mathrm{PLA}_{2}\right)$, simulating generation of arachidonic acid (AA), one of the free fatty acids (FFA). The AA can then be metabolized and converted to prostanoids, such as prostacyclin $\left(\mathrm{PGI}_{2}\right)$, which is a strong smooth muscle relaxant, prostaglandin $\mathrm{G}$, which is a constrictor, thromboxane $\mathrm{A}_{2}\left(\mathrm{TXA}_{2}\right)$, or to leukotrienes (LT), which cause the adherence of leukocytes to vascular endothelium. In addition, it facilitates the conversion of xanthine dehydrogenase (XD) to xanthine oxygenase (XO) and increases the intracellular superoxide radical $\left(\mathrm{O}_{2}{ }^{\circ}\right)$ [23]. Oxygen re-supply after ischemia increases 3 types of ROS: $\mathrm{O}_{2}$, $\mathrm{OH}^{*}$ and LOO $[26]$. These ROS, which are generated mainly in the mitochondria of neutrophils [25], denature the lipid and protein and cause damage to intracellular structures, such as cell membranes and mitochondria (mitochondrial permeability transition pore, MPTP) [27], and can cause denaturation of enzymes [25]. $\mathrm{O}_{2} \cdot$ is the first ROS that is generated by oxygen re-supply. It is produced by XO or by LT from neutrophil and nerve cells in the microvascular structure. A superoxide radical is converted by superoxide dismutase (SOD) to hydrogen peroxide, which is eventually converted to water $\left(\mathrm{H}_{2} \mathrm{O}\right)$ by catalase. In this experiment, catalase pretreatment $(1,000 \mathrm{U} / \mathrm{ml})$ prevented vascular endothelium injury by ROS and a vascular endothelium-dependent aorta relaxation was expressed. However, it was reported that, when $\mathrm{O}_{2} \cdot{ }^{-}$is generated in great quantities $\mathrm{O}_{2}{ }^{-}{ }^{-}$is converted by the Fenton reaction and Haber-Weiss reaction to a hydroxyl radical, which is the ROS that causes the severest injury and eventually causes lipid peroxidation plus cell and tissue injury by LOO generation [26]. In our experiment, pretreatment with mannitol $(5 \mathrm{mM})$, as the $\mathrm{OH} \cdot$ scavenger, did not prevent vascular endothelium injury. Therefore, tests should be conducted using various mannitol doses.

We studied whether the induced rabbit aorta vascular endothelium relaxation caused by ROS is maintained following pretreatment with ketorolac or diclofenac. The result showed that vascular endothelium-dependent relaxation was maintained in proportion to the ketorolac and diclofenac pretreatment doses, verifying their ROS-removing or antioxidizing effect. The induced vascular endothelium-dependent relaxation by ROS was smaller in the diclofenac pretreated group when compared with that of the group treated with the same concentration of ketorolac. This implies that the $\mathrm{IC}_{50}$ for the anti-oxidixing action by diclofenac is larger and thus the ROS-scavenging capacity is smaller when compared with that of ketorolac. Hence, we expect that pretreatment with a high of concentration diclofenac will provide the same effect as that of ketorolac, but with an increased anti-oxidizing effect. On the other hand, Costa et al. [28] reported that non-steroidal anti-inflammatory drugs (NSAIDS) have a hydrogen peroxide scavenging effect. The $\mathrm{H}_{2} \mathrm{O}_{2}$-induced oxidation induced by lucinogen was measured using the chemilumiscence method and the resulting hydrogen peroxide scavenging activity potency ranking was as follows: sulindac sulfone $>$ sulindac sulfide $>\mathrm{GSH}$ (reduced glutathione) $>$ sulindac $>$ indomethacin $>$ acemetacin $>$ etodolac $>$ oxaprozin $>$ ketorolac, melatonin $>$ tolmetin. In our study, hydrogen peroxide experiments were conducted using catalase and 3AT, etc. The induced vascular endothelium relaxation was almost perfectly reproduced, even after the ROS exposure, following pretreatment with the $\mathrm{H}_{2} \mathrm{O}_{2}$ scavenger - catalase. Additionally, pretreatment with 3AT, a catalase inhibitor, resulted in a significant decrease of the induced vascular endothelium-dependent relaxation in the ketorolac group, showing that the hydrogen peroxide scavenging activity is partially involved in the anti-oxidizing activity of ketorolac.

In conclusion, it was shown that ketorolac and diclofenac have an anti-oxidizing effect on ROS or an ROS-removing effect. The hydrogen peroxide-removing effect was partially involved in the protective mechanism of ketorolac against ROS-induced vascular endothelial injury.

\section{References}

1. Wilson JX, Gelb AW. Free radicals, antioxidants, and neurologic 
injury: possible relationship to cerebral protection by anesthetics. J Neurosurg Anesthesiol 2002; 14: 66-79.

2. Hess ML, Manson NH. Molecular oxygen: friend and foe. The role of the oxygen free radical system in the calcium paradox, the oxygen paradox and ischemia/reperfusion injury. J Mol Cell Cardiol 1984; 16: 969-85.

3. Lalu MM, Wang W, Schulz R. Peroxynitrite in myocardial ischemiareperfusion injury. Heart Fail Rev 2002; 7: 359-69.

4. Kato R, Foëx P. Myocardial protection by anesthetic agents against ischemia-reperfusion injury: an update for anesthesiologists. Can J Anaesth 2002; 49: 777-91.

5. Hwang YS, Shin CY, Huh Y, Ryu JH. Hwangryun-Hae-Dok-Tang (Huanglian-Jie-Du-Tang) extract and its constituents reduce ischemia-reperfusion brain injury and neutrophil infiltration in rats. Life Sci 2002; 71: 2105-17.

6. Kapinya KJ, Prass K, Dirnagl U. Isoflurane induced prolonged protection against cerebral ischemia in mice: a redox sensitive mechanism? Neuroreport 2002; 13: 1431-5.

7. Brodsky SV, Yamamoto T, Tada T, Kim B, Chen J, Kajiya F, et al. Endothelial dysfunction in ischemic acute renal failure: rescue by transplanted endothelial cells. Am J Physiol Renal Physiol 2002; 282: F1140-9.

8. Gumusel B, Tel BC, Demirdamar R, Sahin-Erdemli I. Reactive oxygen species-induced impairment of endothelium-dependent relaxation in rat aortic rings: protection by L-arginine. Eur J Pharmacol 1996; 306: 107-12.

9. Furchgott RF, Zawadzki JV. The obligatory role of endothelial cells in the relaxation of arterial smooth muscle by acetylcholine. Nature 1980; 288: 373-6.

10. Palmer RM, Ferrige AG, Moncada S. Nitric oxide release accounts for the biological activity of endothelium-derived relaxing factor. Nature 1987; 327: 524-6.

11. Ebel D, Preckel B, You A, Mullenheim J, Schlack W, Thamer V. Cardioprotection by sevoflurane against reperfusion injury after cardioplegic arrest in the rat is independent of three types of cardioplegia. Br J Anaesth 2002; 88: 828-35.

12. Fernandes E, Costa D, Toste SA, Lima JL, Reis S. In vitro scavenging activity for reactive oxygen and nitrogen species by nonsteroidal anti-inflammatory indole, pyrrole, and oxazole derivative drugs. Free Radic Biol Med 2004; 37: 1895-905.

13. Kil HK, Kim WO, Kim SH, Nam YT. Effects of Isoflurane and Propofol on Hydrogen Peroxide-Induced Injury of Trachea in Guinea-Pig. Korean J Anesthesiol 1999; 37: 303-10.

14. Lamb FS, King CM, Harrell K, Burkel W, Webb RC. Free radicalmediated endothelial damage in blood vessels after electrical stimulation. Am J Physiol 1987; 252: H1041-6.
15. Lamb FS, Webb RC. Vascular effects of free radicals generated by electrical stimulation. Am J Physiol 1984; 247: H709-14.

16. Jackson CV, Mickelson JK, Stringer K, Rao PS, Lucchesi BR. Electrolysis-induced myocardial dysfunction. A novel method for the study of free radical mediated tissue injury. J Pharmacol Methods 1986; 15: 305-20.

17. Jackson CV, Mickelson JK, Pope TK, Rao PS, Lucchesi BR. $\mathrm{O}_{2}$ free radical-mediated myocardial and vascular dysfunction. Am J Physiol 1986; 251: H1225-31.

18. Lecour S, Baouali AB, Maupoil V, Chahine R, Abadie C, JavouheyDonzel A, et al. Demonstration of the production of oxygencentered free radicals during electrolysis using E.S.R. spin-trapping techniques: effects on cardiac function in the isolated rat heart. Free Radic Biol Med 1998; 24: 573-9.

19. Fernandes E, Costa D, Toste SA, Lima JL, Reis S. In vitro scavenging activity for reactive oxygen and nitrogen species by nonsteroidal anti-inflammatory indole, pyrrole, and oxazole derivative drugs. Free Radic Biol Med 2004; 37: 1895-905.

20. Gryglewski RJ, Palmer RM, Moncada S. Superoxide anion is involved in the breakdown of endothelium-derived vascular relaxing factor. Nature 1986; 320: 454-6.

21. Rubanyi GM, Vanhoutte PM. Superoxide anions and hyperoxia inactivate endothelium-derived relaxing factor. Am J Physiol 1986; 250: H822-7.

22. Chen X, Gillis CN. Effect of free radicals on pulmonary vascular response to acetylcholine. J Appl Physiol 1991; 71: 821-5.

23. Lockette W, Otsuka Y, Carretero O. The loss of endotheliumdependent vascular relaxation in hypertension. Hypertension 1986; 8: II61-6.

24. Opie LH. Oxygen lack: ischemia and angina. In: The heart. Physiology, from cell to circulation. 3rd ed. Edited by Opie LH: Philadelphia, Lippincott-Ravens Publishers. 1998, pp 513-41.

25. Opie LH. Myocardial reperfusion: new ischemic syndrome. In: The heart. Physiology, from cell to circulation. 3rd ed. Edited by Opie LH: Philadelphia, Lippincott-Ravens Publishers. 1998, pp 563-88.

26. Safar P, Birtcher NG. Prolonged life support: post-reperfusion syndrome. In: Cardiopulmonary cerebral resuscitation. 3rd ed. Edited by Safar P, Birtcher NG: Philadelphia, WB Saunders Co. 1988, pp 237.

27. Aronis A, Komarnitsky R, Shilo S, Tirosh O. Membrane depolarization of isolated rat liver mitochondria attenuates permeability transition pore opening and oxidant production. Antioxid Redox Signal 2002; 4: 647-54.

28. Costa D, Gomes A, Reis S, Lima JL, Fernandes E. Hydrogen peroxide scavenging activity by non-steroidal anti-inflammatory drugs. Life Sci 2005; 76: 2841-8. 